\title{
Technology development in the solar absorption air-conditioning systems
}

\author{
Z.F. Li, K. Sumathy* \\ Department of Mechanical Engineering, University of Hong Kong, Pokfulam Road, Hong Kong
}

Received 27 August 1999; received in revised form 22 October 1999; accepted 8 November 1999

\begin{abstract}
An environmental control system utilizing solar energy would generally be more costeffective if it were used to provide both heating and cooling requirements in the building it serves. Various solar powered heating systems have been tested extensively, but solar powered air-conditioners have received little more than short-term demonstration attention. This paper reviews past efforts in the field of solar powered air-conditioning systems with the absorption pair of lithium bromide and water. A number of attempts have been made by researchers to improve the performance of the solar applied air-conditioning (chiller) subsystems. It is seen that the generator inlet temperature of the chiller is the most important parameter in the design and fabrication of a solar powered air-conditioning system. While collector choice, system design and arrangement are other impacting factors for the system operation. (C) 2000 Elsevier Science Ltd. All rights reserved.
\end{abstract}

Keywords: Absorption chiller; Air-conditioning; Lithium bromide and water; Solar energy

\section{Introduction}

As a result of the projected world energy shortage, the use of solar energy for environmental control is receiving much attention in the engineering sciences literature. Air-conditioning is a particularly attractive application for solar energy

\footnotetext{
* Corresponding author. Tel.: + 852-2859-2632; fax: + 852-2858-5415.

E-mail address: ksumathy@hkucc.hku.hk (K. Sumathy).
} 
because of the near coincidence of peak cooling loads with the available solar power. Of the air-conditioning alternatives, the absorption system appears to be one of the most promising methods [1]. Many arrangements or cycles are possible: solar collectors can be used to provide energy for absorption cooling, desiccant cooling, and Rankine-vapour compression cycles. Solar hybrid cooling systems are also possible. Although a large potential market exists for this technology, existing solar cooling systems are not competitive with electricity-driven or gas-fired airconditioning systems because of their high first costs. Lowering the cost of components and improving their performance could reduce the cost of solar cooling systems. Improvements such as reduced collector area, because of improved system performance, and reduced collector cost will lower the cost of solar components. Several solar driven refrigeration systems have been proposed and are under development such as sorption systems including liquid/vapor, solid/ vapor absorption, adsorption, vapor compression and photovoltaic-vapor compression systems. Most of the above mentioned systems have not been economically justified.

The main technical problem of solar refrigeration is that the system is highly dependent upon environmental factors such as cooling water temperature, air temperature, solar radiation, wind speed and others. On the other hand, its energetic conversion efficiency is low, and from an economical point of view, solar cooling and refrigeration are not competitive with the conventional systems.

In order to evaluate the potential of the different solar cooling systems, a classification has been made by Best and Ortega [2]. It is based on two main concepts: solar thermal technologies and technologies for cold production. The solar technologies relevant are:

- flat-plate collectors;

- evacuated tube collectors;

- stationary non-imaging concentrating collectors;

- dish type concentrating collectors;

- linear focusing concentrators;

- solar pond;

- photovoltaic; and

- thermoelectric systems.

The cooling technologies are:

- continuous absorption;

- intermittent absorption;

- solid/gas absorption;

- diffusion;

- adsorption; and

- desiccant systems.

The photovoltaic/thermoelectric have predominated in the application of small refrigerators for medical use in isolated areas like vaccine conservation where high system cost is justified. Solar thermal systems, such as flat plate collectors with 
lithium bromide/water absorption cooling systems, are in the stage of preproduction and commercial introduction for small capacities.

Earlier researchers often used the intermittent absorption cycle to produce cooling effect owing to the fact that solar energy is an intermittent heat source [35]. With the development of technologies in continuous absorption cooling systems, especially their higher system performance above intermittent alternatives and their coincidence with the requirement of the air-conditioning (especially for space cooling) demand, continuous solar absorption air-conditioning systems are widely reported and improvements made world-wide.

The performance coefficient of an absorption air-conditioner, defined as the ratio of the heat transfer rate into the evaporator to the heat transfer rate into the generator, can be calculated as a function of the temperatures identified previously. Wilbur and Mitchell [6] compared the coefficient of performance (COP) of absorption systems with different working fluids. Of the various continuous solar air-conditioning systems, $\mathrm{LiBr}-\mathrm{H}_{2} \mathrm{O}$ and $\mathrm{H}_{2} \mathrm{O}-\mathrm{NH}_{3}$ are the major working pairs employed in these systems. It is reported that $\mathrm{LiBr}-\mathrm{H}_{2} \mathrm{O}$ has a higher COP than for the other working fluids. Though it has a limited range of operation, due to the onset of crystallization occurring at the point of the recouperator discharge into the absorber and stopping solution flows through the device, the low cost and excellent performance of this working fluid combination make it the favorable candidate for use in solar cooling cycles.

Also by comparison [6-8], the ammonia-water system has the following additional disadvantages.

- The coefficient of performance (COP) for the $\mathrm{H}_{2} \mathrm{O}-\mathrm{NH}_{3}$ system is lower than for the $\mathrm{LiBr}-\mathrm{H}_{2} \mathrm{O}$ system. Generally, $\mathrm{H}_{2} \mathrm{O}-\mathrm{NH}_{3}$ systems operate at a $10-15 \%$ lower solar fraction than $\mathrm{LiBr}-\mathrm{H}_{2} \mathrm{O}$ systems.

- It requires a higher generator inlet temperature. Generally, $\mathrm{LiBr}-\mathrm{H}_{2} \mathrm{O}$ absorption units require generator inlet temperatures of $70-88^{\circ} \mathrm{C}$, while $\mathrm{H}_{2} \mathrm{O}$ $\mathrm{NH}_{3}$ absorption units require temperatures of $90-180^{\circ} \mathrm{C}$; which results in the $\mathrm{H}_{2} \mathrm{O}-\mathrm{NH}_{3}$ cooling systems achieving a lower $\mathrm{COP}$ when using flat-plate collectors.

- It requires higher pressures and hence higher pumping power.

- A more complex system requiring a rectifier to separate ammonia and water vapor at the generator outlet is required.

- There are restrictions on in-building applications of ammonia-water cooling units because of the hazards associated with the use of ammonia.

For these reasons the lithium bromide-water system is considered to be better suited for most solar absorption air-conditioning applications. Hence, it is the purpose of this study to review the operation of various solar powered absorption air-conditioning systems with lithium bromide and water as the working fluids. As mentioned earlier, the two main concepts to utilize the $\mathrm{LiBr}-\mathrm{H}_{2} \mathrm{O}$ solar-airconditioning system are: cooling technologies and thermal technologies. The major components in the $\mathrm{LiBr}-\mathrm{H}_{2} \mathrm{O}$ solar air-conditioning systems are chillers and solar collectors. Single-effect, double convertible cycle, two-stage, Dual-cycle and other 
chillers are employed as the cooling devices, while flat-plate collectors and evacuated tubular collectors are often used as the thermal power in these kinds of cooling unit. This article details various solar powered absorption air-conditioning systems based on cooling technologies and thermal technologies.

\section{Cooling technologies}

\subsection{Single-effect absorption air-conditioning system}

Fig. 1 shows the schematic diagram of a single-effect solar absorption system; this system has been the basis of most of the experience to date with solar airconditioning. To begin with, the solar energy is gained through the collector and is accumulated in the storage tank. Then, the hot water in the storage tank is supplied to the generator to boil off water vapor from a solution of lithium bromide + water. The water vapor is cooled down in the condenser and then passed to the evaporator where it again is evaporated at low pressure, thereby

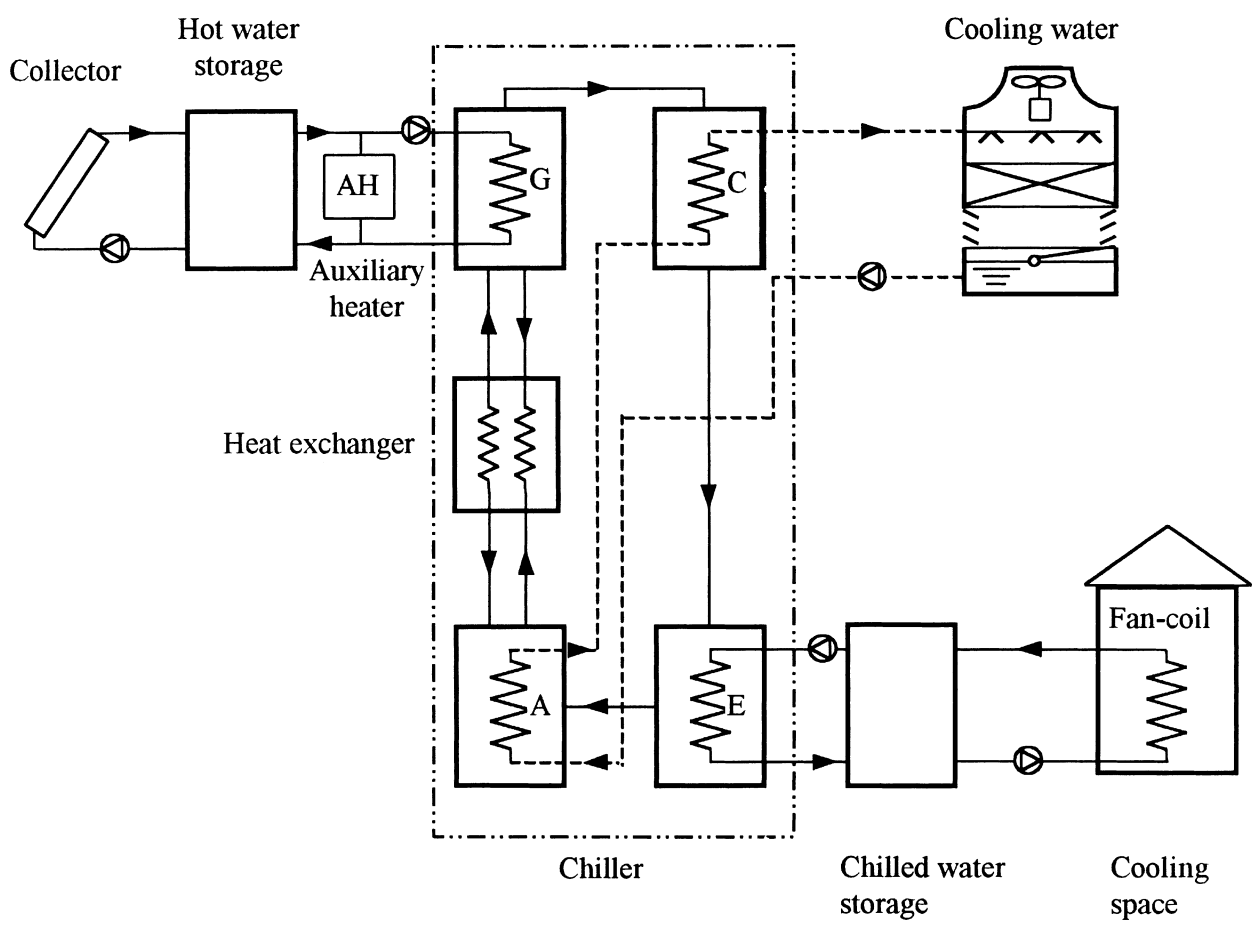

$\mathrm{A}$ - absorber; $\mathrm{G}$ - generator; $\mathrm{C}$ - condenser; $\mathrm{E}$ - evaporator

Fig. 1. Schematic diagram of solar powered single-effect air-conditioning system. 
providing cooling to the required space. Meanwhile, the strong solution leaving the generator to the absorber passes through a heat exchanger in order to preheat the weak solution entering the generator. In the absorber, the strong solution absorbs the water vapor leaving the evaporator. Cooling water from the cooling tower removes the heat by mixing and condensation. Since the temperature of the absorber has a higher influence on the efficiency of the system than the condensing temperature, the heat-rejection (cooling water) fluid, is allowed to flow through the absorber first and then to the condenser [9]. An auxiliary energy source is provided, so that the hot water is supplied to the generator when solar energy is not sufficient to heat the water to the required temperature level needed by the generator.

The main processes taking place in the chiller are as follows (as shown in Fig. 2).

- Line 1-7: The weak solution from the absorber at point 1 is pumped through the heat exchanger to the generator; point 7 indicates the properties of the solution at the outlet of the heat exchanger. During the process 1-7, the concentration of the weak solution is held constant.

- Line 7-2-3: Process 7-2 shows the sensible heating of the weak solution in the generator, and 2-3 indicates the boiling of water vapor from the solution at the

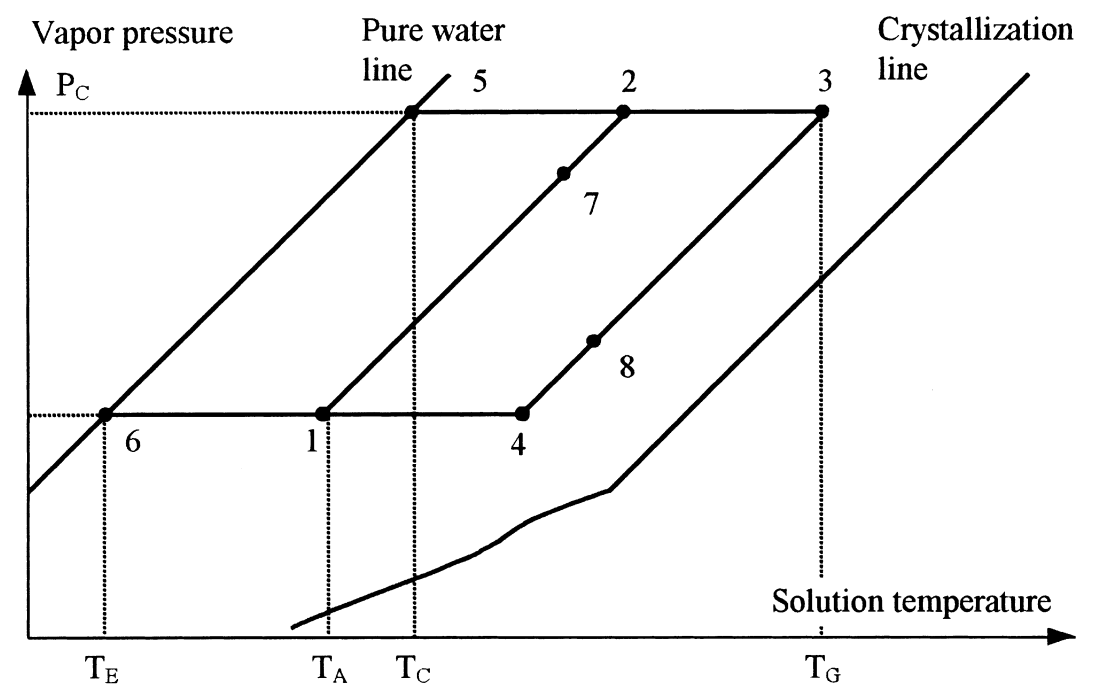

$$
\begin{array}{ll}
\mathrm{P}_{\mathrm{C}}-\text { Condenser pressure; } & \mathrm{P}_{\mathrm{E}}-\text { Evaporator pressure; } \\
\mathrm{T}_{\mathrm{E}}-\text { Evaporator temperature; } & \mathrm{T}_{\mathrm{A}}-\text { Absorber temperature; } \\
\mathrm{T}_{\mathrm{C}}-\text { Condenser temperature; } ; & \mathrm{T}_{\mathrm{G}}-\text { Generator temperature }
\end{array}
$$

Fig. 2. Single-effect absorption cooling cycle. 
constant condensing pressure $P_{\mathrm{C}}$ (although the boiling pressure is little higher than the condensing pressure, the difference is negligible). During this process, the weak solution becomes strong solution.

- Line 3-8: Symbolizes the strong solution passing to the absorber through the heat exchanger, in which it preheats the weak solution flowing from the absorber to the generator. During this process, the concentration of the strong solution is constant.

- Line 8-4-1: Indicates the idealized process of absorption of water vapor from the evaporator by the strong solution in the absorber.

- Line 2-5: Denotes the condensation of water vapor in the condenser by the cooling water from the cooling tower, at constant condensing pressure $P_{\mathrm{C}}$.

- Line 5-6: Shows the flow of condensed water from the condenser to the evaporator.

- Line 6-1: Indicates the evaporation of the water in the evaporator due to the prevailing low pressure $P_{\mathrm{E}}$. Also the water absorbs the heat from the space to be cooled. The water vapor from the evaporator is in turn absorbed by the strong solution in the absorber, thus completing the cycle of refrigeration.

In the solar powered absorption air-conditioning system, it is very much essential to have a hot water storage $[6,10]$. It serves as a buffer reservoir to have nearly constant heat input. Lof and Tybout [11] have reported that the optimum storage volume is about $50 \mathrm{~kg} / \mathrm{m}^{2}$ of collector area. Also, It has been suggested [9] that the nominal storage amounts for cooling purposes range from $80 \mathrm{~kg} / \mathrm{m}^{2}$ of collector area to $200 \mathrm{~kg} / \mathrm{m}^{2}$. A critical problem with the hot water storage tank is its heat loss to the surrounding area. Jacobsen [12] had observed an actual heat loss coefficient of $1.65 \mathrm{~W} / \mathrm{m}^{2 \circ} \mathrm{C}$, which was approximately $50 \%$ greater than the predicted value of about $1.19 \mathrm{~W} / \mathrm{m}^{2 \circ} \mathrm{C}$. Sometimes, the heat loss from the hot water storage tank could be equivalent to $2 \mathrm{~h}$ of operation per day of the solar air-conditioning system [13].

Similar to the hot water storage tank, a chilled water storage tank is often used in the solar powered air-conditioning system [14]. While the hot water storage tank experiences considerable heat loss, the chilled water storage tank has a lower rate of heat gain because of the small temperature difference between the chilled water tank and its surroundings $\left(|\Delta T|_{\text {chilled water tank }}<|\Delta T|_{\text {hot water tank }}\right.$ ). Furthermore, if the chilled water storage tank is installed near the air-conditioned area, its heat gain could assist in cooling.

Generally, a parallel auxiliary-heater arrangement is preferred to the series one [14]. Since the chiller has the best performance at high temperatures (about $88^{\circ} \mathrm{C}$ ), it is better to use the auxiliary heater directly to drive the chiller when the temperature in the hot water storage tank is lower than the required level. If the auxiliary heater is connected in series between the hot water storage tank and the chiller, water is often returned to storage hotter than it is taken out, which raises the storage temperature and decreases the collector efficiency. However, if the storage temperature is below the needed energizing temperature but above the return temperature from the generator, then, a series connection can be 
considered, since only a portion of energy need be supplied by the auxiliary heater to reach the energizing temperature. This method may be suitable in installations needing auxiliary energy only during short periods.

In the heating season, the hot water is directly provided from the hot water storage to the fan-coil of the air-conditioned space, or/and to places where the heat is used for bathing or other domestic applications.

The main parameter that governs the performance of the chiller, is the chilled water temperature. This is because, as the chilled water temperature decreases, the evaporator temperature decreases, thereby decreasing the pressure in the evaporator, all of which finally results in an increased concentration of the solution. This results in the possibility of crystallization of the solution. Also, with the decrease in evaporating temperature, the coefficient of performance (COP) of the chiller would decrease. Therefore, it is suggested that the chilled water temperature should be maintained above $5-7^{\circ} \mathrm{C}$.

For water-cooled air-conditioning systems, the climatic conditions and the availability of the cooling water determine the cooling-water temperature. From the point of view of improving the COP, it is better to use cooling water of low temperature. The normal cooling water temperature is about $25-32^{\circ} \mathrm{C}$. It should also be mentioned that, if the cooling-water temperature is well below the abovementioned temperature range, there is a possibility for crystallization of the solution. Wilbur and Mancini [15] have reported that the wet cooling tower presently used for heat rejection from solar powered absorption coolers is undesirable because it requires maintenance that the average homeowner may be unable to provide and is generally considered unattractive. It is possible to replace it with a lower-performance air-heated exchanger (dry cooling tower). However, the use of a dry cooling tower in place of a wet cooling tower results in a $10-20 \%$ reduction in solar fraction. Therefore, it is suggested that the use of the lower maintenance, aesthetically more acceptable, dry cooling towers should be accompanied by the elimination of hot storage if pressurized storage is to be avoided.

Charters and Chen [16] had made a comparison study on air-cooled and watercooled systems. In the case of a water-cooled system, with a cooling tower, the temperature of heat rejection from the system is directly related to the wet bulb temperature. Whereas, in an air-cooled unit, the heat rejections from the condenser and the absorber are directly related to the out-door dry bulb temperature. For design point, the generally accepted standard is $35^{\circ} \mathrm{C}$ dry-bulb and $25^{\circ} \mathrm{C}$ wet-bulb (established by ASHRAE). Therefore, the cooling temperature needed is higher in the air-cooled system than the water-cooled. Hence, the pressure in the air-cooled system is higher, which decreases the system COP. For example, if the evaporator temperature is $5^{\circ} \mathrm{C}$, and the generator inlet temperature is $78^{\circ} \mathrm{C}$ for a water-cooled system, then, for an air-cooled system under the same conditions, the generator temperature should be raised to above $100^{\circ} \mathrm{C}$. This temperature is above the effective operating temperature range of the present day flat-plate solar collectors. In addition, Charters and Chen have conducted experiments with a high concentration of $\mathrm{LiBr}$, very close to the crystallization 
limit of the solution. It was seen that a sudden drop in temperature in the generator would cause the formation of crystals and "shut-down" of the system. To overcome this problem, it was suggested that the addition of some salts (such as $\mathrm{LiSCN}$ ) to the $\mathrm{LiBr}-\mathrm{H}_{2} \mathrm{O}$ solution is necessary in order to lower the solution vapor pressure and thereby improve the solution characteristics for use in an aircooled system. The addition of LiSCN is claimed to lower the vapor pressure and hence prevent crystallization of the solution at the temperature prevalent in an aircooled system. Even if it is possible to use this new working fluid with an aircooled absorption refrigeration system, the generator temperature required will still be above $100^{\circ} \mathrm{C}$.

Butz et al. [17] had presented a detailed thermal and economical analysis of a solar heated air-conditioning system. The solar collector was modeled in the manner proposed by Hottel and Whillier [18], Bliss [19], and Klein et al. [20] in which the thermal capacitance of the collector is neglected. The analysis of the thermal performance indicated the dependence of output on collector area (considered as the primary design variable) and showed, for example, the manner in which annual system efficiency decreases as collector area increases.

The above analysis was modified by $\mathrm{Hu}$ [21]. In his work, he simulated the system performance by considering unsteady heating in the collector; thereby, including the thermal capacitance of the collector components in obtaining the useful energy.

Blinn et al. [22] have developed a transient model of a $\mathrm{LiBr}-\mathrm{H}_{2} \mathrm{O}$ airconditioner and applied it to a simulation of residential solar air-conditioning systems in the southern United States. In a system controlled by an on-off room thermostat, chiller transients were found to degrade system performance significantly. Increasing the room thermostat dead-band would decrease the frequency of cycling, improve system performance and decrease auxiliary energy consumption. For the flat-plate collectors used, the highest solar fraction was obtained at the lowest source temperature. A comparison of three auxiliary strategies indicated that parallel heat auxiliary led to a higher fraction by solar than did series heat auxiliary. Vapor compression led to a slightly higher fraction by solar than either of the heat auxiliary modes and required less auxiliary energy.

The capacity and the COP of the chiller are generally taken as a function of entering hot water and cooling-water temperatures, and are formulated with the performance curves provided by the manufacturer or by experiments. A detailed numerical simulation model was developed by Muneer and Uppal [23], for a commercially available solar absorption chiller. They have shown that the coolingwater temperature is a function of water inlet temperature, to the tower and ambient wet-bulb temperature. The model incorporates the performance data of a Yazaki-manufactured water-cooled system. Using a summer season's meteorological data for an arid location in the Sahara desert, the system performance has been computed for different collector types, areas and storage volumes. The results show that an optimum storage volume/collector area ratio exists. The interesting feature was that the system operated at design load 
conditions with generator temperatures as low as $80^{\circ} \mathrm{C}$ owing to the fact that very low cooling-water temperatures are available in the dry conditions of the Sahara.

Numerical models to assist in design of solar assisted air-conditioning systems are available in several forms. TRNSYS [24] provides digital simulation of solar cooling systems, and models for each component by a subroutine, so that input references can link each output to the corresponding input of another component. The Commission of the European Communities by University College Dublin has also provided a detailed description of the simulation of the solar thermal systems [25].

Through the application of the first and second laws of thermodynamics, Mansoori and Patel [26] have derived upper and lower limits for the coefficient of performance (COP) of absorption cooling cycles. It is shown that these upper and lower limits, besides being dependent on the environmental temperatures of components of the cycle, are also dependent on the thermodynamic properties of refrigerants, absorbents, and their mixtures. With the use of these upper and lower limits of COP, it is possible to make a quantitative comparative study of different refrigerant-absorbent combinations. The technique developed is applied for the comparative evaluation of $\mathrm{H}_{2} \mathrm{O}-\mathrm{NH}_{3}, \quad \mathrm{NH}_{3}+\mathrm{NaSCN}$ and $\mathrm{LiBr}-\mathrm{H}_{2} \mathrm{O}$ combinations which are the favorable candidates used in solar absorption cooling cycles.

\subsection{Single-effect system with refrigerant storage}

One of the improvements that would make the absorption machine more suitable for solar operation is refrigerant storage. Basically, the idea is to provide, in association with the condenser, a storage volume where the refrigerant can be accumulated during the hours of high solar insolation. Then, this stored liquid refrigerant can be expanded at other times to meet the required loads. Storage is also needed in the absorber to accommodate not only the refrigerant but also sufficient absorbent to keep the concentration within allowable limits.

The advantages of refrigerant storage over other methods include:

- the energy storage per unit volume is high as the latent heat of evaporation, which is larger, compared to available sensible heat changes, is involved;

- losses are low as the storage occurs at or near room temperature;

- further advantages arise when the storage is applied to the lithium bromidewater cycle;

- water has one of the highest enthalpies of evaporation among known liquids;

- the storage pressure is low so that the strength of the storage vessel is not critical.

Fig. 3 shows the schematic of the single-effect cooling system [27]. The refrigeration circuit includes the usual generator, condenser, evaporator and absorber together with a sensible heat exchanger, a mechanical pump and pressure reducing valves or equivalent. A refrigerant store is associated with the condenser while an absorber store is associated with the absorber. Heat rejection is 
accomplished by a cooling tower from which water is circulated through the absorber, condenser store and condenser in series. Other water circuits could be used: indeed there may be some advantages to be gained in using parallel operation, notably the cooler water available for the condenser and the possibility of shutting off flow to the condenser altogether when there is no generation.

Room air is circulated through the evaporator, and is maintained at a constant temperature, within the limits of the room thermostat and air-conditioner, by operating an on-off valve in the refrigerant line before the evaporator.

A solar powered air-conditioning system of this type was modeled based on the above conception and geographical data in Brisbane, Australia [28]. They have reported that the generation of refrigerant ceases several hours before sunset although a significant amount of energy is still being collected. The stoppage occurs because of the high boiling point of the solution that has become highly concentrated with so much refrigerant in the store. During the night as the refrigerant flows from the store to the absorber, the evaporator cooling rate continually decreases as the solution concentration decreases and causes a higher pressure and temperature in the evaporator. Fortunately, the building load has also decreased.

Wilbur et al. $[6,15]$ have worked on a similar system and their experience shows that the systems with refrigerant storage and heat rejection buffer, require smaller

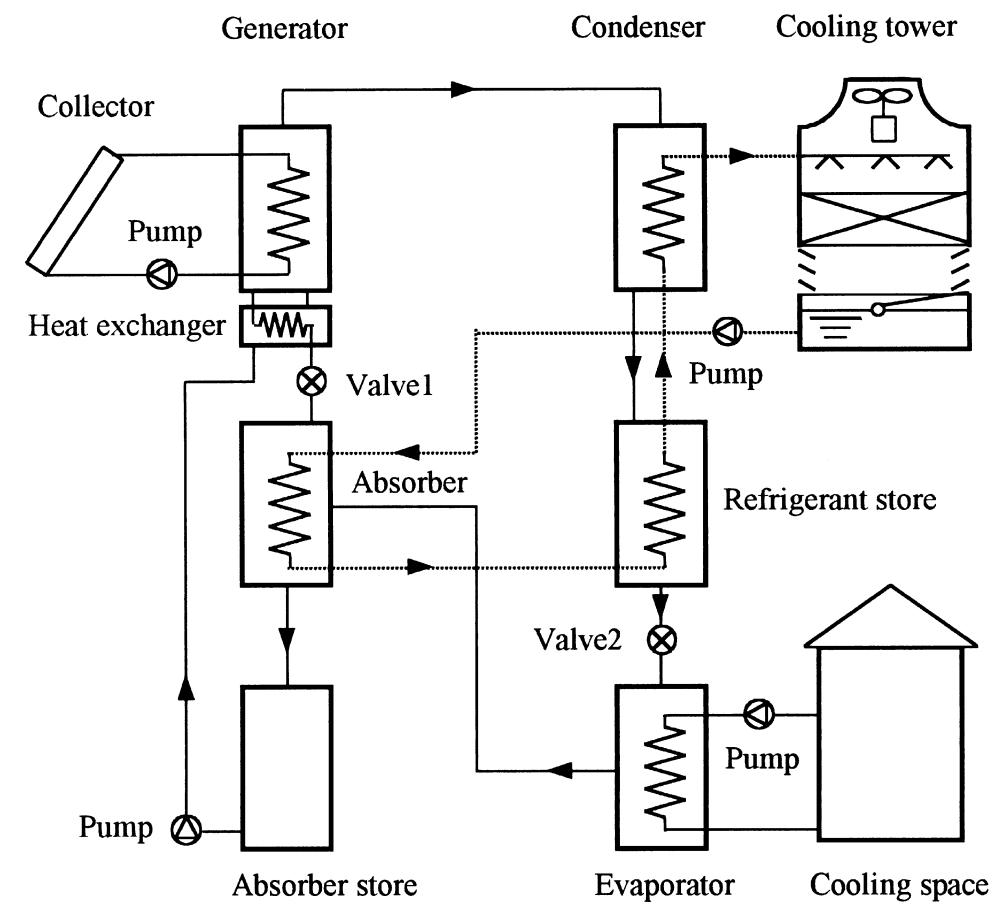

Fig. 3. Flow chart of the solar cooling system with refrigerant storage. 
cooling towers than conventional units. In such a system, hot water from the collector could be passed directly through the generator of a single stage absorption system to generate refrigerant at any time when collector temperatures were sufficient to cause vaporization in the generator. The refrigerant would be condensed at the time of generation and would be available at a later time when air-conditioning was needed. If a cooling demand removed the entire stored refrigerant, then auxiliary heat would have to be supplied to generate refrigerant.

A water tank used for heat storage during the winter months would not be required in such a system. It could, however, be used to advantage if it were cooled continuously by a cooling tower and if its contents circulated through the absorber and condenser to receive heat rejected from the conditioner. In this configuration, the water tank (heat rejection buffer) could be cooled to near the ambient wet-bulb temperatures during periods of low heat rejection, and it should facilitate system operation at lower peak absorber/condenser temperatures and hence lower generator temperatures. In addition, such a configuration should permit use of a smaller cooling tower operating continuously near the mean, rather than peak heat rejection rate, for the system. The disadvantages of the kind system may be that:

- generation of refrigerant ceases several hours before sunset and although a significant amount of energy is still being collected, a lot of useful solar energy is wasted;

- the system may be very complicated. The generation power is not easily matched with the absorption and refrigeration power; besides, the control of valves 1 and 2 is difficult;

- although the machine could store sufficient refrigerant during a typical day to allow overnight operation, the performance of the chiller is very low because of the decrease in concentration of the solution and the increase of the temperature and pressure in the system.

\subsection{Single-effect system with hot water storage}

Efficient operation can be achieved by using two hot storage units for the collection of solar energy in different temperature ranges [9]. One storage would provide $70-75 \%$ of the total heat required at the lowest temperature which can be utilized effectively at the part-load conditions. Typical temperature may be from 50 to $70^{\circ} \mathrm{C}$ depending on the building load pattern and the expected pattern of ambient temperature. The remaining $25-30 \%$ of the storage volume would be in a smaller tank with more insolation in order to store the heat collected in $85-95^{\circ} \mathrm{C}$. Still higher temperatures may be used in this storage if it can be pressurized to prevent boiling, and if collectors are used which are capable of operating at higher temperature levels with good efficiency. Latent heat storage may be particularly worthwhile in the higher-temperature unit since it tends to reduce its physical size for a given amount of $\mathrm{kWh}$ stored, and provides more heat at the levels needed 
for full-load operation without significant temperature change. In Fig. 4, the pump $\mathrm{P}$ circulates the liquid from either the low or high temperature storage. Valves 1 and 2 are opened when the system is to add heat to the low temperature storage L, and valves 3 and 4 are opened for adding heat to the higher temperature storage $\mathrm{H}$. Control $\mathrm{C}$ determines when the pump operates and which valves are opened.

The control of the dual storage solar cooling system is indicated in Fig. 5. The pump is turned on whenever the difference in temperature between the sensors $\mathrm{S}$, and $\mathrm{L}$ or $\mathrm{H}$ is positive and large enough to indicate that sufficient insolation exists to begin to charge the storage. Choice is also made as to which storage is to receive the heat. The control sequence is typical and the detailed description is as follows:

1. Sensor $\mathrm{S}$ measures a representative temperature of the collector array. It may, for example, be attached to the liquid outlet tube at the top of one of the collectors or to the collector absorber. Before sunrise it will substantially be at the ambient temperature and therefore below the temperature of the low temperature storage $\mathrm{L}$.

2. As soon as the sun warms the collectors so that the sensor temperature exceeds that of the low-temperature storage sensor $\mathrm{L}$, the solid state device energizes relay $R_{1}$ to start the pump and open valves $V_{1}$ and $V_{2}$. The stored liquid is then circulated to the low-temperature collector to add heat.

3. As insolation increases, the temperature differential between $\mathrm{S}$ and $\mathrm{L}$ increases, until the control stops the pump at a predetermined difference. It is an indication, that heat can be collected in a significant amount at the higher temperature. At this time the collector closes all valves for a short time interval of 2-3 min. The best time interval will vary from one installation to another and hence some adjustment of this interval is desirable.

4. If during the time interval of step 3, the sensor $\mathrm{S}$ reaches a temperature above that in the high-temperature storage as measured by sensor $\mathrm{H}$, the solid state device (differential temperature controller) restarts the pump and opens valves

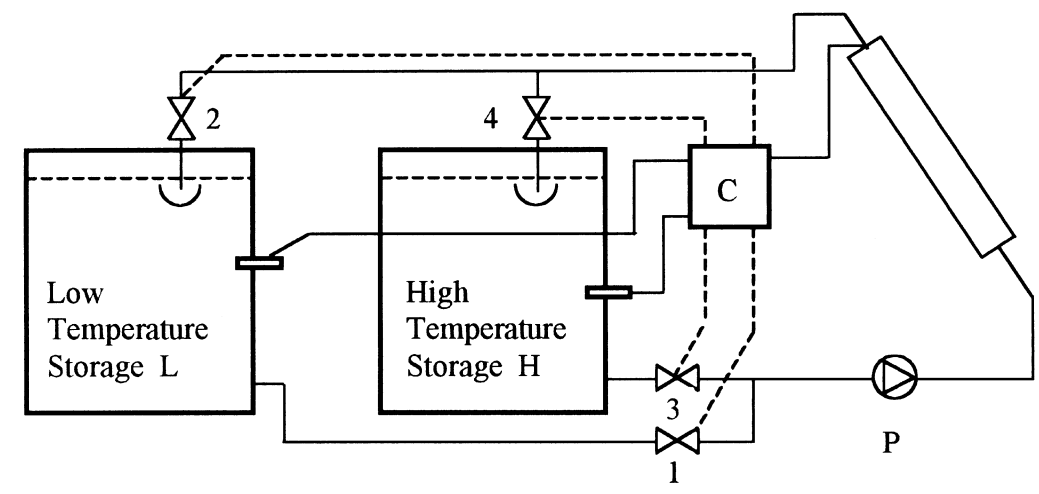

Fig. 4. Dual storage schematic diagram. 
$\mathrm{V}_{3}$ and $\mathrm{V}_{4}$ to add heat to the high-temperature storage. If the required temperature level is not reached within the 2-3-min time-interval, the control restarts the pump and opens valves $V_{1}$ and $V_{2}$ to continue collection of heat into the low temperature storage. The solid state device may include a time function which assures that the operation in the low temperature mode will continue for a minimum time such as 15 or 30 min to prevent frequent cycling from high to low temperature storage.

5. The solid state device may also use the temperature sensed by either $\mathrm{H}$ or $\mathrm{L}$ as a high limit to discontinue heat into either storage when its maximum desired storage temperature is reached. This action prevents boiling or other unsafe operation.

The advantages of the above system are that separation of the storage into a high and low temperature subsystems may increase the heat collected by a given collector array by a factor of 1.30-1.50, depending on location and type of collectors. At the same time, the COP on a seasonal basis may rise from approximately 0.65 to 0.75 , a $15 \%$ improvement. Taken together these benefits may decrease the required collector area to cool a given building by $30-40 \%$ - a considerable saving.

\subsection{Double-effect convertible system}

As technical development of absorption chillers allowed for lower generating temperatures as low as $73^{\circ} \mathrm{C}$, the percentage of the solar contribution to air-

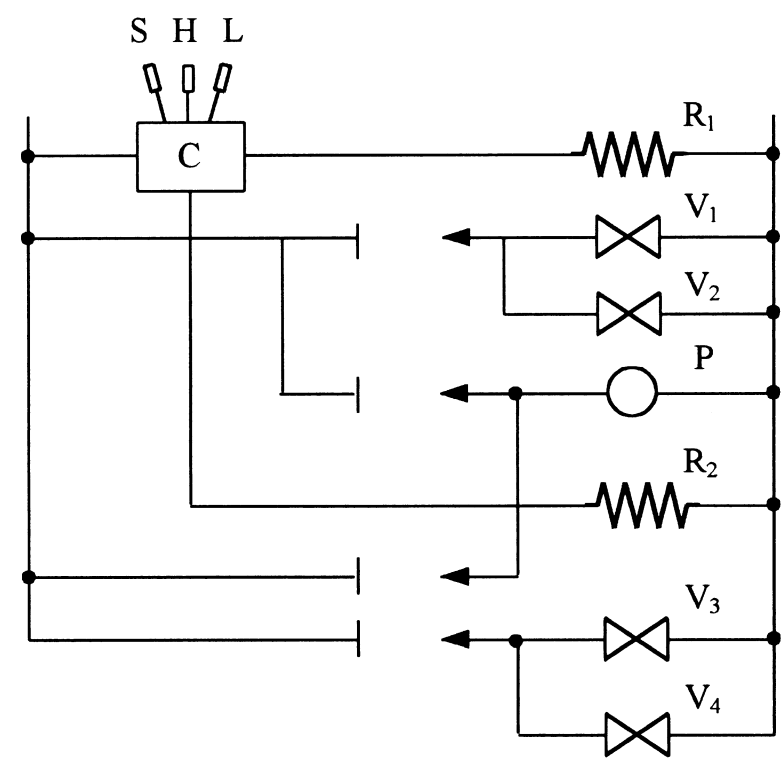

Fig. 5. Control of dual storage solar cooling system. 
conditioning became higher. However, if it worked at a lower COP with the same generation temperature when conventional fuel was used as the auxiliary, it would not be considered sensible. Some years ago an absorption chiller was introduced [29] that works in double effect principle by using fuel at a higher COP, and in single effect using solar energy, so as to achieve an overall high coefficient of performance.

The principle of the system is explained using Fig. 6; it is fundamentally a double effect absorption chiller where in the weak solution is circulated in series. In addition to the components listed in the single effect system, the double effect convertible system has a high pressure generator, a secondary heat exchanger and a heat recovery unit [30].

The high-pressure generator for steam is independently located from the lowpressure generator for solar and hot water vapor from the high-pressure generator before being condensed. A high-pressure generator gives a primary effect and a low-pressure generator a secondary effect, thus being called a double effect. Therefore, a double effect cycle requires lower heat input to produce the same cooling effect, when compared to a single effect system. Therefore, a double effect system results in higher COP.

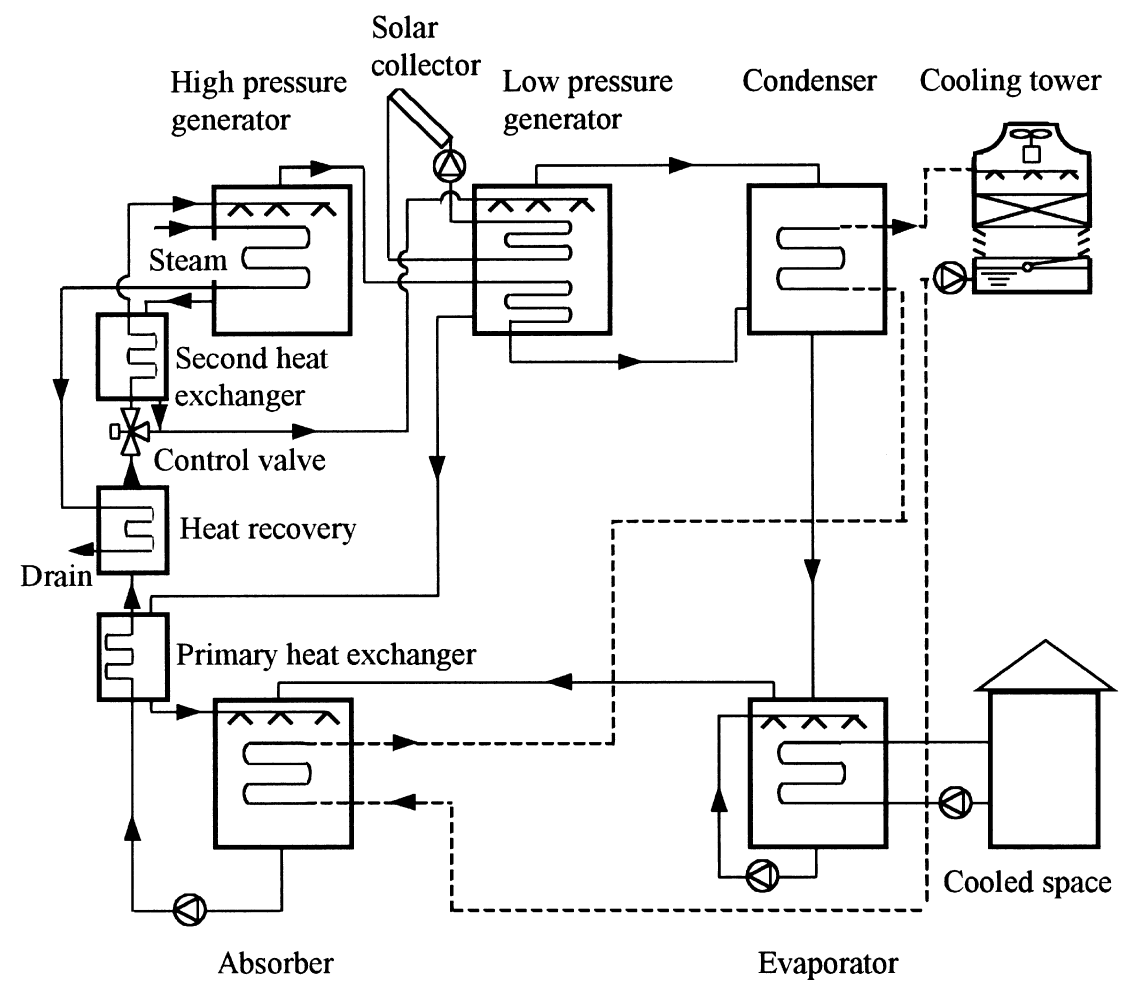

Fig. 6. Single/double effect convertible absorption cooling system. 
As shown in Fig. 6, during the refrigeration circulation, the water vapor produced in the high-pressure generator, heats the solution in the low-pressure generator, thereby giving up its heat, and then is passed to the condenser. Meanwhile, the generated water vapor in the low-pressure generator also passes to the condenser. The condensed water vapor is then passed to the evaporator to collect heat from the space to be cooled, thereby producing the refrigerating effect. Obviously, compared to the single effect system, the double effect cycle has an additional advantage of having a reduced condensing demand.

Similarly, in the solution circulation, the double effect is again realized by circulating the solution from the absorber to the high-pressure generator through the primary and secondary heat exchangers and the heat recovery unit. This process preheats the weak solution. Also, the strong solution from the highpressure generator is circulated to the low-pressure generator and is then allowed to pass through the primary heat exchanger back to the absorber, for mixing. If solar energy is used in the system as the heating source, then, the control valve will be such that the weak solution from the absorber will be directly fed to the low-pressure generator through the primary heat exchanger and heat recovery unit.

This kind of machine was originally suggested by Tanaka, it was first installed at a new building of the Energy Engineering Department of Oita University, Kyushu [31]. After successful operation for a two-year test period, the solar airconditioning system was operated with steam as the auxiliary fuel. The identical single-double effect absorption chiller was also operated at the Kabe Office Building of the Chugoku Electric Company in Hiroshima.

Double effect absorption chillers ranging from $2 \mathrm{RT}$ (tons of refrigeration) to 10 $\mathrm{RT}$ in modular designs are also available. If the customer needs a larger capacity than 10-ton chillers, multiple 10-ton units may be installed so that some work under the conditions of lower solar intensity and less cooling load by automatic control. The performance of the smaller machines is almost the same as the larger ones. They use the bubble pumping effect in transporting the $\mathrm{LiBr}$ solution from the generator absorber, while larger ones use a circulating pump for that purpose.

\subsection{Two-stage system}

One of the restrictions for the practical use of the single stage cooling system is an economical aspect - the capital cost of the system is too high. It is reasonable to lower the solar collector cost by using collector models of a lower temperature range, if the generator temperature of the chiller can be lowered by using a twostage $\mathrm{LiBr}$ absorption chiller instead of single-stage chiller. Therefore, to bring down the initial cost of the system, the important variable is the generating temperature. Alizadeh et al. [32] have pointed out the advantage of lowering the generator temperature:

1. the ordinary flat-plate collectors can be employed, thereby bringing down the 
cost of the system; and

2. crystallization of $\mathrm{LiBr}-\mathrm{H}_{2} \mathrm{O}$ solution could be avoided.

In order to search for an approach to a more economical solution of solar cooling, a two-stage $\mathrm{LiBr}$ absorption chiller prototype, working on lower temperature heat source, has been designed and tested successfully by Huang et al. [33]. Initially, the two-stage $\mathrm{LiBr}$ absorption cooling machine was designed for the purpose of low temperature industrial waste heat recovery, but it seems also suitable for solar cooling application.

Fig. 7 shows the flowchart of the two-stage absorption chiller. The cycle is divided into high-pressure stage and low-pressure stage. Diluted $\mathrm{LiBr}$ solution in the high-pressure generator is heated by hot water. Generated water vapor is condensed in the condenser. The condensed water flows into the evaporator (lowpressure stage) to be evaporated, producing the refrigerating effect. A concentrated solution from the high-pressure generator enters into the highpressure absorber and absorbs water vapor generated from the low-pressure generator, thus changing back to a diluted solution. This solution is then pumped back to the high-pressure generator, completing a high-pressure cycle. The concentrated solution in the low-pressure generator goes down into the lowpressure absorber and absorbs water vapor from the evaporator. The diluted solution from the low-pressure absorber is then pumped back to the low-pressure generator, completing a low-pressure cycle. Thus, refrigerant water is made in the high-pressure stage and the absorbent-concentrated solution is made in the lowpressure stage. So, through the high-pressure absorption process, the generation process in the low-pressure generator occurs under a lower pressure, completing a full refrigeration cycle.

Fig. 8 shows the enthalpy-concentration diagram of the two-stage system; it can be seen that, the high-pressure absorber and the low-pressure generator are at the same pressure, say $2.73 \mathrm{kP}_{\mathrm{a}}$; and because of the use of the two-stage system, the generator temperature has decreased to as low as $66^{\circ} \mathrm{C}$. Experiments indicated that, for the single-effect system, when the heat medium temperature decreases below nominal (about $85^{\circ} \mathrm{C}$ ), cooling capacity and COP decrease drastically. The two-stage system, however, can use heat sources of a lower temperature to achieve better cooling effect under more severe conditions.

In January 1998, a solar powered two-stage absorption air-conditioning system was installed in China [34] and the schematic is shown in Fig. 9. The system has a cooling power of $100 \mathrm{~kW}$, with collector areas of $500 \mathrm{~m}^{2}$. The nominal generating temperature of the chiller is about $65-75^{\circ} \mathrm{C}$, and the COP of the chiller is greater than 0.4. The two-stage system has the following advantages:

1. the cooling system can work steadily though solar input is unsteady;

2. the lower generator inlet and outlet temperatures both increase instantaneously and daily efficiencies of solar collector system;

3. a required lower operating temperature provides the possibility to use a simpler model of a solar collector, e.g., flat-plate collectors, instead of vacuum-tube 


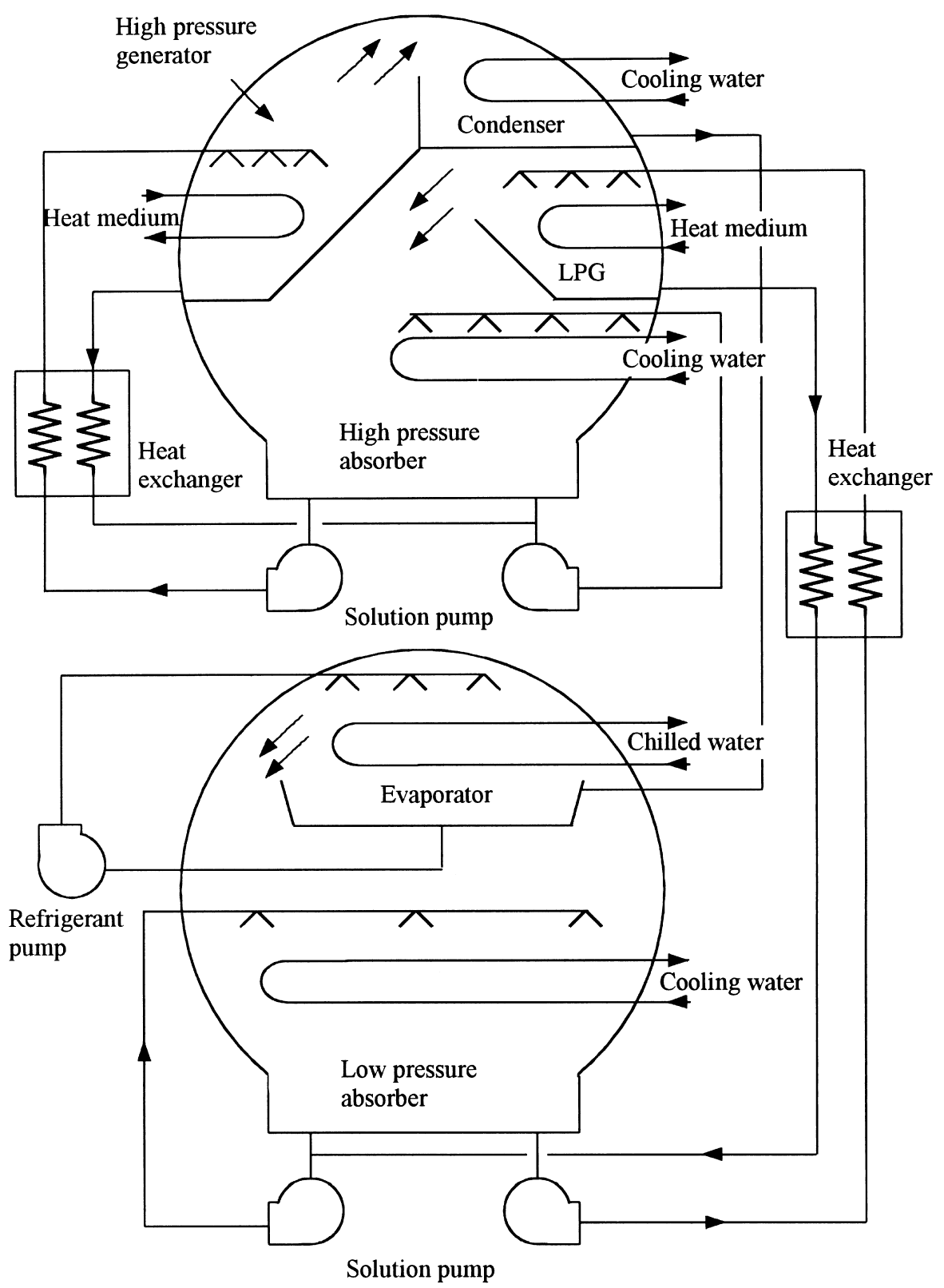

LPG - Low pressure generator

Fig. 7. Schematic diagram of the two-stage absorption chiller. 
collectors, which are 3-4 times more expensive than the flat-plate collectors, thus reducing the construction cost of the solar system.

The disadvantages of this system are the complexity of the chiller's construction, and the COP at the nominal generator temperature is lower than the single-effect one. Meanwhile, the amount of cooling water needed is double that of the singleeffect one, so that the cooling tower should be larger.

Kaushik and Kumar [35] introduced a two-stage dual fluid absorption refrigeration. The system uses $\mathrm{LiBr}-\mathrm{H}_{2} \mathrm{O}$ and $\mathrm{H}_{2} \mathrm{O}-\mathrm{NH}_{3}$ as working fluids at the first and second stage, respectively. Fig. 10 shows the schematic diagram of this system, which consists of two stages. The first stage operates through a $\mathrm{LiBr}-\mathrm{H}_{2} \mathrm{O}$ combination, while the second stage uses a $\mathrm{H}_{2} \mathrm{O}-\mathrm{NH}_{3}$ combination. Therefore, a rectifier is needed only at the second stage and is avoided at the first stage. The first stage is assumed to operate with the condenser and absorber maintained at a temperature of $30^{\circ} \mathrm{C}$ by the circulation of cooling water, and the evaporator operated at a temperature of $5^{\circ} \mathrm{C}$. In the second stage, the absorber is assumed to be maintained at $5^{\circ} \mathrm{C}$ by the evaporator of the first stage. The operation principles at the second are the same as for the first except that a rectifier is needed for the purification of ammonia vapor. Also, an evaporator temperature as low as $-20^{\circ} \mathrm{C}$ can easily be produced at the second stage.

Through the system analysis, they found that at the second stage, low condenser temperatures can yield a better performance at lower generator temperatures but at higher generator temperatures, a high value of COP is obtained at a higher condenser temperature. Secondly, an increase in the COP

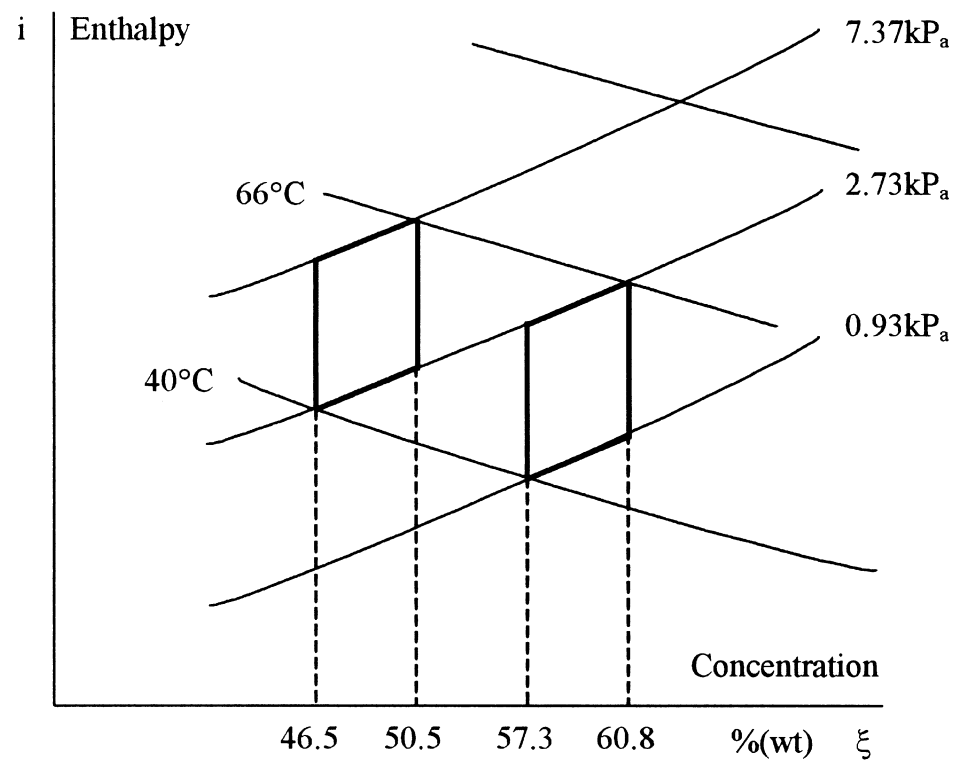

Fig. 8. Diagram of two-stage absorption cooling cycle. 
value with the evaporator temperature is more within the lower generator temperature range than for the higher generator temperatures. Furthermore, it is evident that lower evaporator temperatures require either higher generator temperatures or lower absorber temperatures.

A two-stage dual fluid absorption system can be operated with ordinary flatplate collectors at the first stage and evacuated tube solar collectors at the second stage for the production of very low evaporator temperatures. The COP of the system is lower than the $\mathrm{LiBr}-\mathrm{H}_{2} \mathrm{O}$ two-stage system, but higher than the $\mathrm{H}_{2} \mathrm{O}$ $\mathrm{NH}_{3}$ two-stage system.

\subsection{Dual-cycle system}

Although, the above mentioned absorption systems use solar energy directly with minimum conversion, they consume considerable quantities of water for the cooling tower. This is a serious disadvantage where solar energy is available whilst water is scarce. The dual cycle, however, may be used in arid areas. It has the advantage of avoiding the use of the wet cooling tower. However, its COP is very

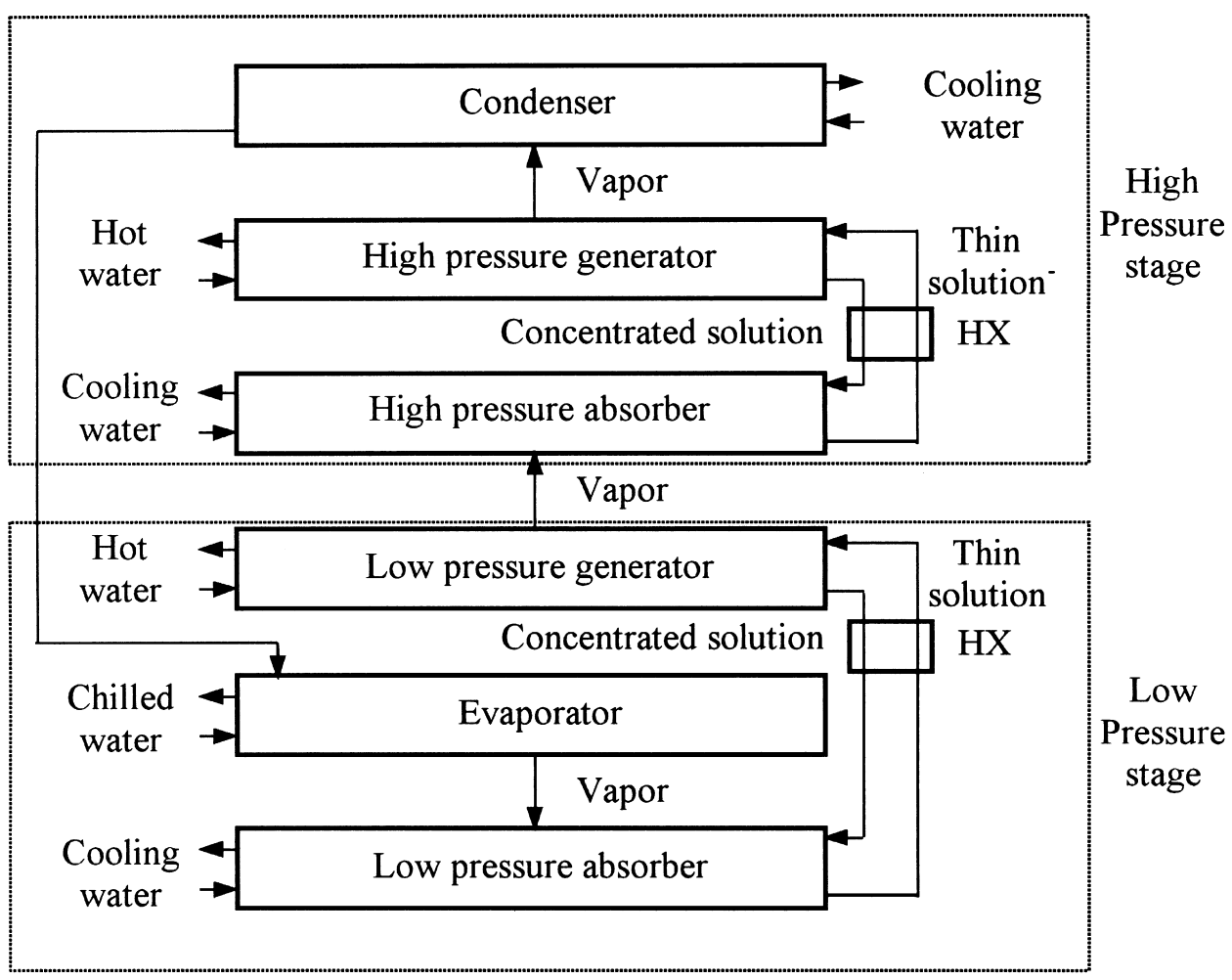

Fig. 9. Flow chart of two-stage chiller system. 


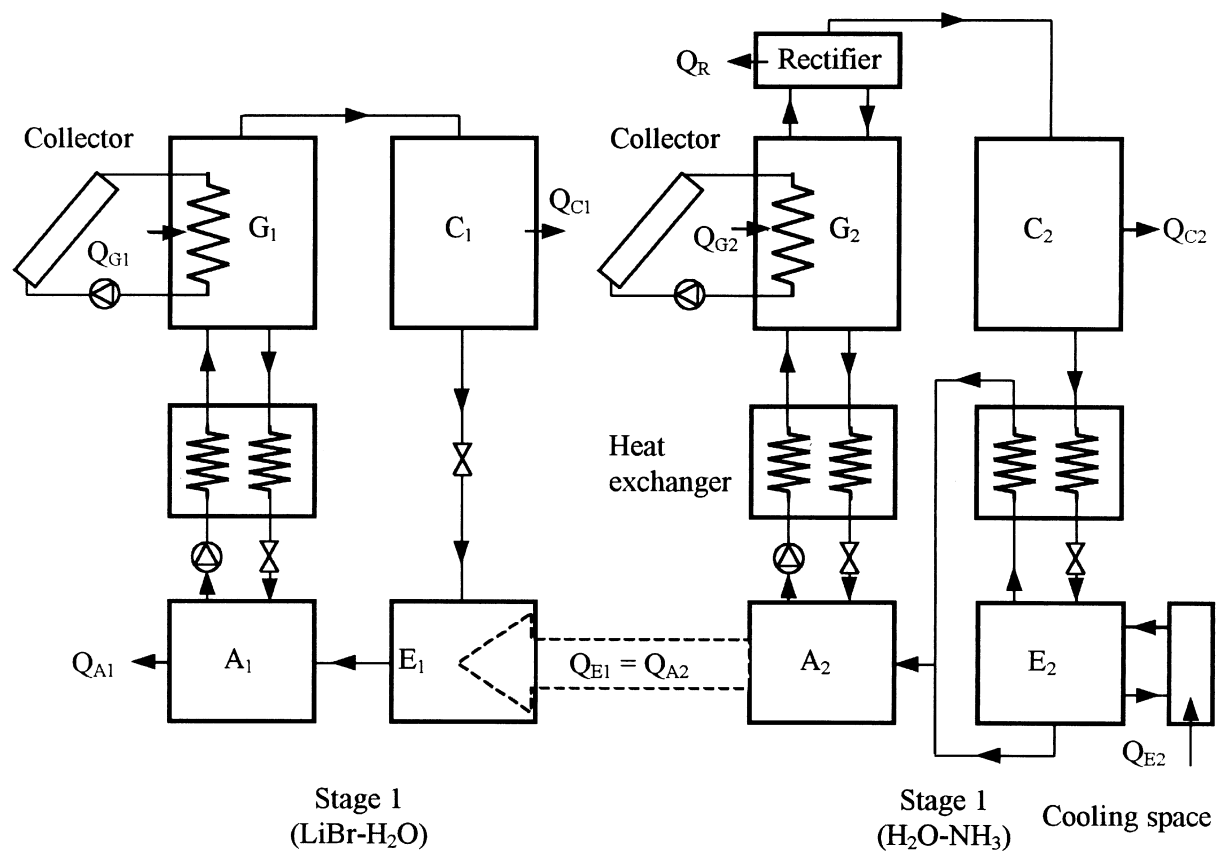

Fig. 10. Diagram of two-stage dual fluid solar absorption cycle.

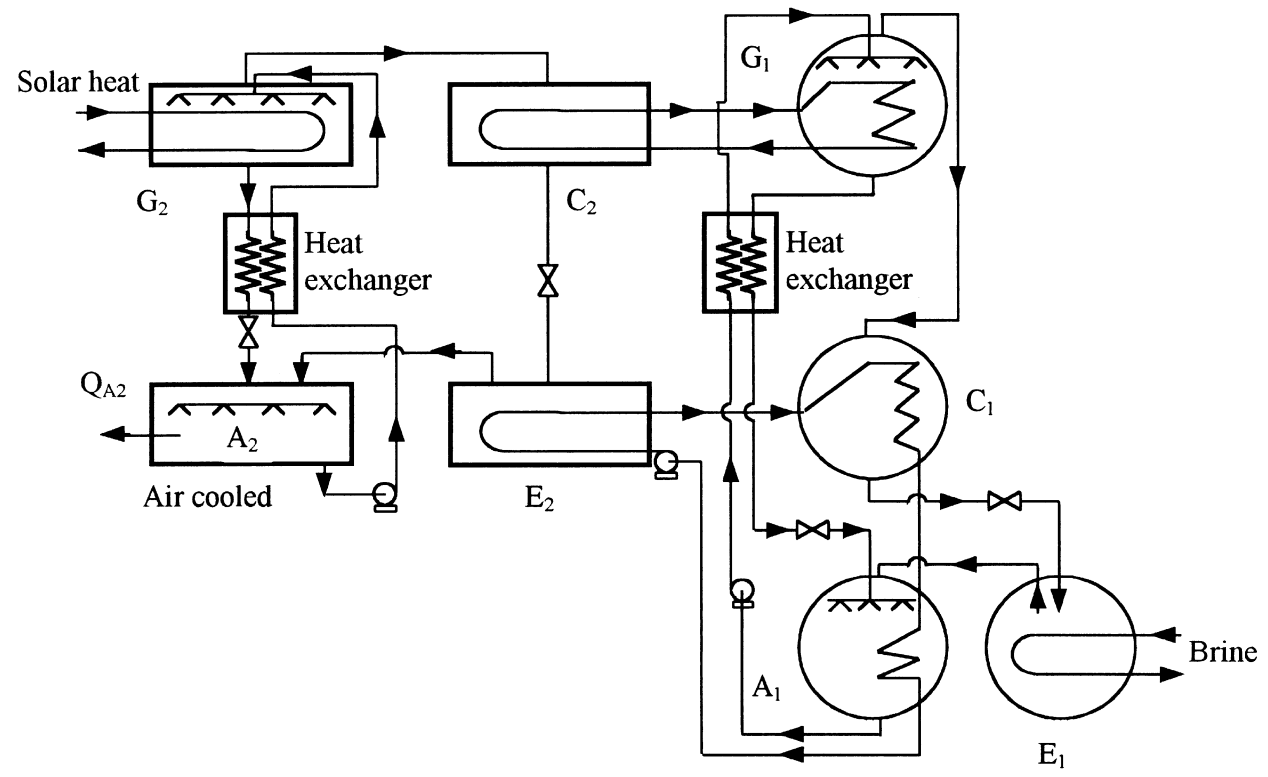

Fig. 11. Dual-cycle block diagram. 
low. Sofrata et al. [36] have introduced the LiBr-absorption cycle which avoids the use of a wet cooling tower. Fig. 11 shows the schematic diagram of the dual cycle solar powered air-conditioning system, and Fig. 12 shows such a cycle on a PTX diagram [37]. The dual cycle consists of a high- and a low-temperature cycle. Each cycle is similar to a conventional single-effect absorption cycle. The main heat energy supplier to the generator of the high temperature level cycle (HTLC) may be solar energy. The HTLC absorber rejects its heat to the atmosphere and this is the main advantage of using such a cycle. The cooling effect of the system will be through the low temperature level cycle (LTLC) evaporator. At this stage, the heat exchange between the system as a whole and the environment has been accomplished.

The interchange of heat between the HTLC and LTLC occurs as follows. The HTLC condenser supplies heat energy to the LTLC generator. The temperature level of this heat supply should be high enough to generate water vapor in the LTLC. The HTLC evaporator will serve as a heat sink for both the absorber and the condenser of the LTLC. At this stage, also, the heat exchange between the two cycles has been completed. The heat balance requires, for both the HTLC and the LTLC, that the sum of the heat supplied to the generator and the cooling effect by the evaporator must equal the heat rejected by the condenser and the absorber. Simultaneously, for the best design, the LTLC condenser heat must just equal the heat required for the LTLC generator. In addition, the cooling effect of the HTLC must equal the sum of the heat rejected by the LTLC of the absorber

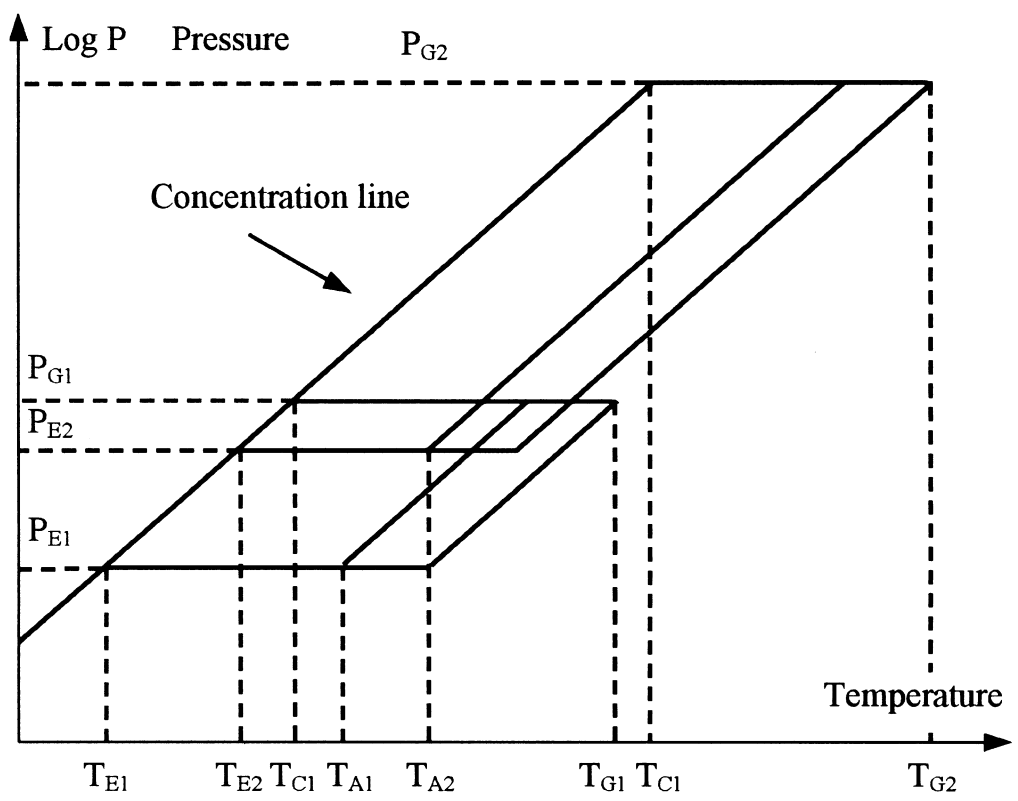

Fig. 12. PTX diagram of dual-cycle. 
and the condenser. With these points in mind and to satisfy the physical constraints (crystallization and water icing) of the $\mathrm{LiBr}$ and water working pair, tedious calculations may be needed to construct the dual cycle.

Since the dual system requires higher generating temperatures, evacuated tube collectors should be used. In addition, the whole system is very complicated as compared with the single-effect one. The dual system is appropriate for locations where solar energy is available but where water is scarce, as the cooling tower may be eliminated.

\subsection{Triple-effect system and multistage system}

Absorption technology may be extended to a multistage system. When solar energy is not available, auxiliary heat (fuel) would be used for the absorption airconditioning system. Triple-effect systems are currently being developed by manufactures and researchers [38]. However, these units are currently not commercially available.

In a triple-effect cycle, higher $\mathrm{COP}$ is obtained by adding a topping cycle to a double-effect machine. In order to achieve three effects (using the heat three times), the heat of condensation from the topping-cycle refrigerant and the heat produced in the topping-cycle absorber section are used to power the high-stage generator of the double-effect cycle. The heat of condensation for the high-stage refrigerant is used to power the low-stage generator, just as in a double-effect $\mathrm{LiBr}$ machine. The refrigerant for the system is shared by all three parts of a tripleeffect machine (topping, high stage, and low stage). Due to the high temperatures needed to power the topping cycles, the triple-effect systems currently under development will all be direct-fired machines. A typical generator temperature of approximately $250^{\circ} \mathrm{C}$ is used for the heat input to the topping cycle. The attainable cooling COP for a triple-effect machine is approximately 1.5.

\section{Thermal technologies}

\subsection{Conventional flat-plate collectors and evacuated tube collectors}

A flat-plate collector is generally used in the solar powered $\mathrm{LiBr}-\mathrm{H}_{2} \mathrm{O}$ absorption air-conditioning systems, due to its low costs. It is better to use two or three glass covers $[11,39]$, or a convection suppressing device in the collector in order to achieve high collected temperatures. Selective coated absorbers with single-glass covered flat-plate collectors were also employed in many systems [4042]. Ward et al. [8] have pointed out that the use of evacuated tubular solar collectors permits the collection of solar energy at lower solar radiation levels (about $0.14 \mathrm{~kW} / \mathrm{m}^{2}$ vs $0.25-0.30 \mathrm{~kW} / \mathrm{m}^{2}$ for flat-plate collectors), and thus provides solar energy for heating and cooling earlier in the morning and later in the evening. This increases the availability of solar radiation during those periods of load demand. In addition, the greater strength and durability of cylindrical 
glass tubes over a sheet of flat glass means that wind and hail would be much less of a threat to the structural integrity of an evacuated glass tube. And, because of the lower cover temperature of the evacuated tube, the wind will have less effect on the efficiency of the collector. Wilbur and Mancini [15] indicated that the high performance of an evacuated collector effects a $10-30 \%$ increase in solar fraction above that observed with the conventional flat-plate collector.

In places where a dry cooling tower is used instead of a wet cooling tower, the system performance would be degraded if hot water storage were employed. To improve the performance, the hot water storage tank could be avoided by employing evacuated tube collectors instead of conventional flat-plate collectors to meet with the heat demand.

Dan Ward along with John Ward [43] have indicated that, the potential disadvantage of the evacuated tube solar collectors is that they may not be able to withstand the high equilibrium (no flow) temperatures they develop either during installation or later during electrical power failures. For evacuated tube collectors, slight variation in the flow through a tube in parallel may easily result in boiling (and thus the loss of the usefulness of the tube) because of the exceptionally low heat loss coefficient of these collectors. In applications where there is a snow overnight, snow removal requires longer melting periods than conventional flatplate collectors because snow slide-off is generally impeded by the geometrical shape and tubular design of the evacuated tube solar collectors. For evacuated tube collectors, a stagnation temperature (the stagnation temperature is the temperature of the absorber under an equilibrium, no-flow condition of the collector heat transfer fluid) of $280^{\circ} \mathrm{C}$ was observed by Ward et al. [8] for a solar intensity of $769 \mathrm{~W} / \mathrm{m}^{2}$. Such a condition emphasizes the need for careful design of the solar heating and cooling operation. For example, the control systems should be able to prevent the boil of the collector fluid, destruction of the collector loop, degradation or destruction of the solar collector or its components, and avoid the safety hazards of high-pressure steam discharge.

In designing the solar powered absorption air-conditioning system, lowering the required generating temperature is very important, as it influences the collector efficiency effectively. For example, if the liquid coming from hot water storage is at $70^{\circ} \mathrm{C}$ rather than $90^{\circ} \mathrm{C}$, then, more than double the heat can be collected through the collector, and more than four times the amount of heat can be collected at $50^{\circ} \mathrm{C}$ than at $90^{\circ} \mathrm{C}$. Systems thus benefit from collecting and storing heat at lower temperatures at which it can be effectively used. Although focusing collectors can also be used in the system, they can only absorb the direct-beam component of solar energy. This fact must be considered when designing collector arrays in geographical areas where clouds frequently cover major portions of the sky for a high percentage of the time. Focusing collectors will also need power for motion tracking.

\subsection{Usage of solar pond to replace conventional collectors}

The possibility of using solar ponds as low-cost solar collectors combined with 
conventional absorption chillers in a large-scale solar-cooling design was investigated by Tsilingiris [44]. Fig. 13 details the working principle of the above mentioned system. The lower convection zone (LCZ) of the solar pond provides the hot brine to the generator, while the upper convection zone (UVZ) provides the low temperature water to the condenser and absorber, so that the cooling tower is avoided. The flow rate of brine through the chiller should be designed carefully and is limited to a velocity of less than $1 \mathrm{~m} / \mathrm{s}$. The experiments from both the small and large size ponds have shown that, the lateral separation of withdrawal and injection heat extraction flow distributors can be located at the same side of the pond adjacent to the power plant since a small temperature drop is sufficient to vertically separate the flows. Therefore, the assumption of well mixed convection zones will not always be realized in practice, since return flow from the condenser and absorber will form a warmer surface region within the UCZ and a cooler fluid region within the LCZ, respectively. Fortunately, both these effects have a favorable influence on chiller capacity by decreasing the heat flux to the soil and increasing the flux to the environment.

The difficulties involved with the construction of large scale solar cooling at a competitive cost are related to the prohibitively high costs of advanced technology high-temperature collectors. The optimum pond area at which capital cost is minimized has been reported for a given chiller size. The derived cost per unit $\mathrm{kW}$ depends mainly on salt cost and ranges from about $\$ 300-500 / \mathrm{kW}$, figures which are almost an order of magnitude lower than those corresponding to a large scale cooling installation using evacuated tube solar collectors. The comparison of solar pond with flat-plate collectors also shows that the solar pond is more effective at higher temperatures with built-in heat storage at substantially lower cost [45]. The

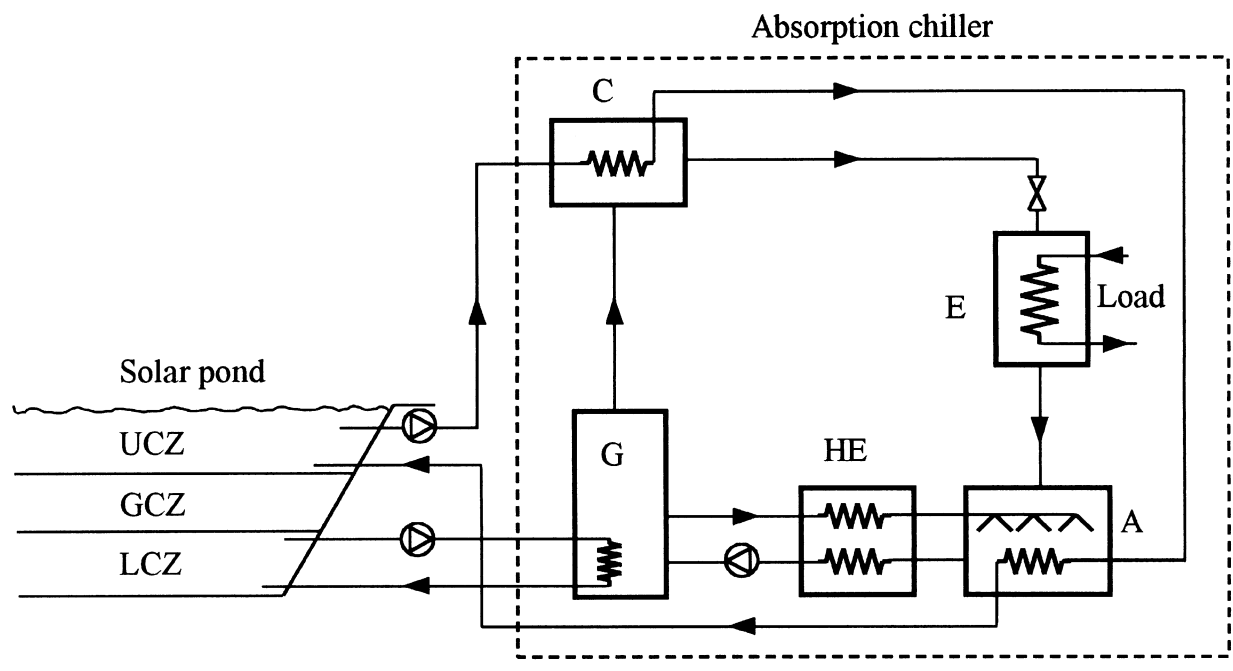

Fig. 13. Diagram of solar pond air-conditioning system. 
disadvantages of this kind of system may be the staining of salt in the heat exchanger of the chiller, which decreases the heat transfer from the solar pond to the chiller.

\section{Conclusion}

Solar absorption air-conditioning has the advantage of both the supply of the sunshine and the need for refrigeration reach maximum levels in the same season. Although solar powered air-conditioning systems are readily available in commercial sizes, existing solar cooling systems are not competitive with conventional electricity-driven or gas-fired air-conditioning systems because of their high first cost. Several technical problems associated with the design and development of absorption chillers based on continuous cycles have been successively resolved, and new trends gradually developed towards the redesign of the chiller generator for operation at temperatures lower than $100^{\circ} \mathrm{C}$.

Of the two main technologies of solar cooling systems discussed in this paper, the emphasis is placed on the cooling technology rather than on the thermal technology, which places an important factor in increasing the COP of the refrigeration systems. It is shown that although the single-effect system with refrigerant storage has the advantage of accumulating refrigerant during the hours of high solar insolation, the double-effect convertible system has a higher overall COP. And the two-stage system has the advantage of lowering the generator temperature, which improves the system performance and the use of conventional flat-plate collectors to achieve high COP. There are many other achievements carried out by researchers, nevertheless, further improvements should be made to the solar powered air-conditioning systems in order to compete with the conventional air-conditioning systems.

\section{References}

[1] ASHRAE. Absorption air-conditioning and refrigeration equipment. In: ASHRAE Guide and Data Book, Equipment. Chapter 14. New York: ASHRAE, 1972.

[2] Best R, Ortega N. Solar refrigeration and cooling. In: World Renewable Energy Congress V, 20 25 September, Florence, Italy II, 1998. p. 685-90.

[3] Sakada, Suzuki M. Simultaneous transportation of heat and adsorbate in closed type adsorption cooling system utilizing solar energy. Journal of Solar Energy Engineering 1986;108:239-45.

[4] Pons M, Grenier P. Journal of Solar Energy Engineering 1987 Experiment data on a solarpowered ice maker using activated carbon and methanol adsorption pair;109:303-10.

[5] Critoph RE. Performances limitations of adsorption cycles for solar cooling. Solar Energy 1988;41:21-31.

[6] Wilbur PJ, Mitchell CE. Solar absorption air-conditioning alternatives. Solar Energy 1975;17:1939.

[7] Ward DJ. Solar absorption cooling feasibility. Solar Energy 1979;22:259-68.

[8] Ward DS, Duff WS, Ward JC, Lof GOG. Integration of evacuated tubular solar collectors with lithium bromide absorption cooling systems. Solar Energy 1979;22:335-41. 
[9] Kreider JF, Kreith F. Solar systems for space cooling. In: Solar energy handbook. New York: McGraw-Hill, 1981.

[10] Lazzarin RM, Boldrin B. Experimental investigation on control modes for an absorption chiller of low capacity. In: Proceedings of the ISES, Silver Jubilee Congress Atlanta, Georgia, May, 1979. vol. 1. p. 710-4.

[11] Lof GOG, Tybout RA. The design and cost of optimized systems for residential heating and cooling by solar energy. Solar Energy 1974;16:9-18.

[12] Jacobsen AS. Solar heating and cooling of mobile homes, test results. In: Proceedings of the 1977 Annual Meeting of the American Section of the International Solar Energy Society, Orlando, Florida, 1977. p. 1.

[13] Ward DS, Lof GOG. Design, construction and testing of a residential solar heating and cooling system. Report to the Committee on the Challenges of Modern Society (CCMS) Solar Energy Pilot Study, July 1976.

[14] Ward DS, Smith CC, Ward JC. Operational models of solar heating and cooling systems. Solar Energy 1977;19:55-61.

[15] Wilbur PJ, Mancini TR. A comparison of solar absorption air-conditioning systems. Solar Energy 1976;18:569-76.

[16] Charters WWS, Chen WD. Some design aspects of air cooled solar powered $\mathrm{LiBr}-\mathrm{H}_{2} \mathrm{O}$ absorption cycle air-conditioning systems. In: Proceedings of the ISES, Silver Jubilee Congress, Atlanta, Georgia, May 1979. vol. 1. p. 725-8.

[17] Butz LW, Beckman WA, Duffie JA. Simulation of a solar heating and cooling system. Solar Energy 1974;16:129-36.

[18] Hottel HC, Whillier A. Evaluation of flat-plate solar collector performance. In: Transcripts of the Conference on Solar Energy, University of Arizona, II (Thermal Processes), 1955. p. 74-104.

[19] Bliss RW. The derivation of several "plate efficiency factors" useful in the design of flat plate collectors. Solar Energy 1959;3(4):55-64.

[20] Klein SA, Duffie JA, Beckman WA. Transient considerations of flat-plate solar collectors. Trans ASME, Journal of Engineering for Power 1974;96A:109.

[21] $\mathrm{Hu} \mathrm{HL}$. Computer simulation and system performance analysis of the solar powered airconditioning and heat providing system. Master thesis, Guangzhou Institute of Energy Conversion, Chinese Academy of Sciences, 1991.

[22] Blinn JC, Mitchell JW, Duffie JA. Modeling of transient performance of residential solar airconditioning systems. In: Proceedings of the ISES, Silver Jubilee Congress, Atlanta, Georgia, May 1979. vol. 1. p. 705-9.

[23] Muneer T, Uppal AH. Modeling and simulation of a solar absorption cooling system. Applied Energy 1985;19:209-29.

[24] TRNSYS. A transient system simulation program. Solar Energy Laboratory, University of Winconsin-Madison, Engineering Experimental Station Report 38, June, 1979.

[25] Dutre WL. Simulation of thermal systems - a modular program with an interactive preprocessor (EMGP3). Dordrecht: Kluwer Academic Publishers, 1991.

[26] Mansoori GA, Patel V. Thermodynamics basis for the choice of working fluids for solar absorption cooling systems. Solar Energy 1979;22:483-91.

[27] Grassie SL, Sheridan NR. Modeling of a solar-powered absorption air-conditioning system with refrigerant storage. Solar Energy 1977;19:691-700.

[28] Sheridan NR, Kaushik SC. A novel latent heat storage for solar space heating systems: refrigerant storage. Applied Energy 9:165-72.

[29] Sayigh AAM, McVeigh, JC. Solar absorption cooling. In: Solar Air-conditioning and Refrigeration. Chapter 3. UK: Pergamon Press Ltd.

[30] Dai YQ. Technology and application of $\mathrm{LiBr}$ absorption refrigeration. In: China: Chinese mechanical engineering industry publication, 1997.

[31] Ishibashi T. The operation results of the Yazaki Experimental Solar House, Silver Jubilee Congress of ISES, Atlanta, May 1979.

[32] Alizadeh S, Bahar F, Geoola F. Design and optimization of an absorption refrigeration system operated by solar energy. Solar Energy 1979;22:149-54. 
[33] Huang ZC, Xia WH, Ma WB. A 2-stage LiBr absorption chiller for solar cooling. In: Proceedings of the Biennial Congress of ISES, Denver, Colorado, USA, 19-23 August, 1991. vol. 2. p. 1643-8.

[34] Guangzhou Institute of Energy Conversion. Progress reports on the solar-powered airconditioning and hot water providing system. Guangzhou institute of energy conversion, Chinese Academy of Sciences, 1998.

[35] Kaushik SC, Kumar R. Computer-aided conceptual thermodynamic design of a two-stage dual fluid absorption cycle for solar refrigeration. Solar Energy 1985;35:401-7.

[36] Sofrata HM, Khoshaim B, Nasser A, Megahed M. A solar-powered Li-Br dual cycle. Applied Energy 1981;9:185-91.

[37] Sofrata HM, Abdul-Fattah AF. Solar-powered dual absorption system: selection criteria using fuzzy decision analysis. Applied Energy 1982;11:223-32.

[38] Dorgan CB, Leight SP, Dorgan CE. Other technologies. In: Application Guide for Absorption Cooling/Refrigeration using Recovered Heat. Chapter 11. USA: ASHRAE.

[39] Nakahara N, Miyakawa Y, Yamamoto M. Experimental study on house cooling and heating with solar energy using flat plate collector. Solar Energy 1977;19:657-62.

[40] Parker Jr AJ, Cassel DE, Hedden RE. Application of solar cooling for a school building in subtropics. In: Proceedings of the First International Conference, Solar/80, Caracas, Venezuela, 36 August, 1980. p. 55-76.

[41] Yeung MR, Yuen PK, Dunn A, Cornish LS. Performance of a solar-powered air-conditioning system in Hong Kong. Solar Energy 1992;48:309-19.

[42] Izquierdo M, Hernandez F, Martin E. Solar cooling in Madrid: available solar energy. Solar Energy 1994;53:431-43.

[43] Ward DS, Ward JC. Design considerations for residential solar heating and cooling systems utilizing evacuated tube solar collectors. Solar Energy 1979;22:113-8.

[44] Tsilingiris PT. The absorption chiller in large scale solar pond cooling design with condenser heat rejection in the upper convecting zone. Solar Energy 1992;49:19-27.

[45] Kooi CF. The steady-state solar pond. Solar Energy 1979;23:37-45. 